\title{
ANÁLISE E IMPLICAÇÕES DO USO TECNOLOGIA DE INFORMAÇÃO NA MELHORIA DE PROCESSOS LOGÍSTICOS
}

\author{
ANALYSIS AND IMPLICATIONS OF USE OF INFORMATION \\ TECHNOLOGY IN THE IMPROVEMENT OF LOGISTICS PROCESS
}

\author{
Diego Augusto de Jesus Pacheco ${ }^{1,}$, Renato Winther Tubino²
}

\begin{abstract}
RESUMO
O objetivo desta pesquisa foi analisar como as ferramentas da Tecnologia de Informação podem ser aplicadas para alcançar melhorias nos processos de distribuição logística. $\mathrm{O}$ estudo explora o impacto da implantação de duas ferramentas usadas na gestão de logística: leitores de códigos de barras, e coletores de dados com leitores RFID (Radio Frequency Identification). A automação industrial se faz necessária para que as empresas de hoje se tornem eficientes e competitivas, já que o uso da conferência eletrônica resulta em velocidade e confiabilidade aos processos. Quanto aos procedimentos de pesquisa adotados, esse estudo possui abordagem qualitativa, de natureza aplicada através de um estudo de caso em profundidade em um empresa de distribuição de produtos veterinários brasileira. Foram utilizados métodos qualitativos e quantitativos de coleta e análise de dados. Os resultados obtidos, através do estudo, demonstram que, a partir da implantação de leitores de códigos de barra, ocorrerá redução de custos com fretes, tempo com retrabalhos e perda de produtos.
\end{abstract}

Palavras-chave: Armazenagem, distribuição, tecnologia da informação, processos logísticos.

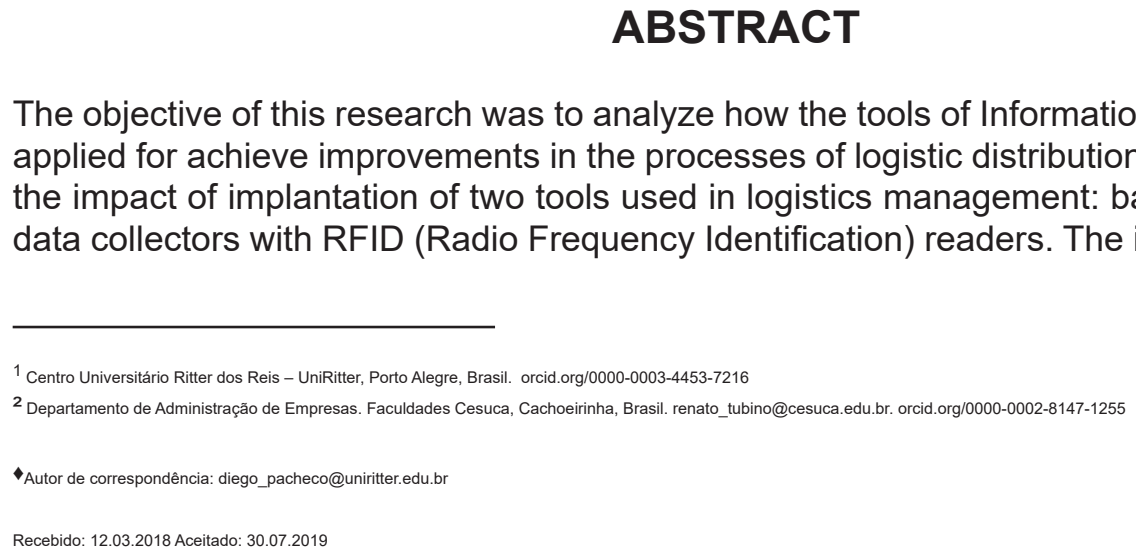


is necessary for the enterprises to become efficient and competitive, since the use of electronic conferencing results in velocity and process reliability. Regarding the research procedures adopted, this study adopted a qualitative approach, applied in an in-depth case study at a Brazilian veterinary distribution company. Qualitative and quantitative methods of data collection and analysis were used. The results obtained, through the study, demonstrate that, from the implantation of readers of bar codes, will occur reduction of costs with freights, time with rework and loss of products.

Keywords: Storage, distribution, Information technology, logistics processes.

\section{INTRODUÇÃO}

É notório que as empresas necessitam se aperfeiçoar constantemente para se adequar a um mercado em evolução. Além disso, hoje a economia é fortemente influenciada pela comunicação, em que as empresas têm enfrentado um ambiente complexo e de competição acirrada (Santos \& Alves, 2015). A conferência eletrônica se faz necessária para que uma empresa esteja adequada competitivamente. Neste estudo abordaremos ferramentas que facilitariam a acuracidade de estoque, minimizando eventuais erros de separação de produtos e auxiliando no armazenamento e nos controles logísticos.

Para ser competitivo, avalia-se o desempenho dos processos através de indicadores. Sob esse enfoque, a avaliação de desempenho usando indicadores de performance tem uma importância fundamental para o desenvolvimento de qualquer organização. Nesse sentido, diversos estudos (Menegatti et al., 2012; Moraes et al., 2012; Oliveira, 2007) afirmam que avaliar os desempenhos de seus processos geram informações importantes para executar melhorias nos serviços prestados pelos processos logísticos.

Nos dias de hoje, é notável que as empresas necessitam de melhorias contínuas em seus processos em todas as áreas considerando que o avanço tecnológico facilitou o uso de novas ferramentas tecnológicas. Além disso, os modelos de gestão da logística aplicados atualmente não atingem satisfatoriamente seus objetivos e frequentemente há disparidade entre a realidade e benefícios (Santos \& Alves, 2015). As mudanças aceleradas na ciência, tecnologia, economias e outros, exigem mudanças nas formas de pensar e agir corporativo (Echeverri et al., 2010).

Como consequência dessas mudanças, o controle de estoque passa a representar uma das operações logísticas mais importantes na gestão das cadeias de suprimentos (OrjuelaCastro et al., 2017). Em produtos perecíveis cujo prazo/tempo de validade é uma variável crítica a ser controlada somada ao custo, a gestão de estoques acurada se torna ainda mais necessária e crítica. Esse é o caso por exemplo dos processos de armazenagem e distribuição de produtos veterinários.

Neste contexto, se embasa o problema de pesquisa e a justificativa da escolha do tema da presente pesquisa. A empresa de distribuição de medicamentos veterinários analisada nesse estudo apresenta dificuldades quanto a acuracidade de estoques e elevados índices históricos de erros nos processos de separação dos pedidos. Além disso, a pesquisa por artigos na base de dados Scielo e Scopus não apresentou resultados de estudos explorando 
esse tema em particular, sob a perspectiva da tecnologia de informação, e em particular o uso de leitores de códigos de barras, e coletores de dados com leitores de RFID.

Embora a informação desempenhe papel fundamental nos processos logísticos, o seu uso efetivo somente tem sido possível graças à evolução da tecnologia com sistemas mais inteligentes e sofisticados (Bertaglia, 2006). Santos e Alves (2015) corroboram a relevância do tema afirmando que a eficiência na gestão da demanda é impactada pelo fluxo de informações, onde interferências podem resultar em redução do nível de serviço, e problemas no giro dos estoques.

Nessa mesma linha de discussão, o planejamento dos processos logísticos se torna fundamental, podendo prevenir problemas relacionados a compras, e atraso na entrega de produtos ao cliente final. Assim, se insere o tema da logística empresarial, que estuda como a administração pode melhorar rentabilidade nos serviços estocagem e distribuição através de planejamento logístico (Ballou, 1993). Como efeito negativo, a falta de planejamento pode dificultar os processos para que a empresa tenha um bom desempenho nos processos de distribuição de produtos.

Para atingir os objetivos estratégicos nos processos de distribuição de produtos é necessário planejar a compra e armazenagem dos produtos de acordo com o espaço disponível na área de estocagem. Logo, se faz necessário planejar as áreas de recebimento e expedição contemplando definir os materiais a serem recebidos e expedidos, determinar as docas de recebimento e necessidade de espaço para movimentação (Moura, 1989). Se os espaços para movimentação forem respeitados, o processo se tornará mais eficiente.

Assim sendo, considerando as discussões anteriores o principal objetivo da presente pesquisa é analisar como a tecnologia da informação, aplicada na gestão de estoques, auxilia na melhoria dos processos de distribuição logística com o objetivo de sanar divergências no estoque com troca de produtos e retrabalhos. Nesse caso, ênfase particular será dada ao impacto do uso leitores de códigos de barras, e coletores de dados com leitores RFID.

Estudos mostram que existem novas tecnologias mais adequadas a serem aplicadas hoje aos processos de distribuição, avaliando as melhores oportunidades a serem utilizadas em melhoria dos processos de armazenamento da empresa, com a finalidade de implantar tecnologias que possam deixar a empresa investigada mais competitiva. É notório que o tempo utilizado hoje nos processos logísticos tende a ser cada vez mais rápido e eficiente devido à competitividade entre as empresas. Além disso, atualmente, clientes, fornecedores e concorrentes estão cada vez mais sensíveis a uma capacidade de movimentação rápida de produtos (Razzolini, 2007).

O presente artigo foi organizado em cinco seções. A seção dois apresenta os principais conceitos relacionados a distribuição logística e a tecnologia da informação. A terceira seção descreve os procedimentos de coleta e análise de dados, assim como o contexto do estudo de caso. A seção posterior trás as informações qualitativas e quantitativas dos resultados obtidos ao longo da pesquisa. A discussão e ponderação das implicações dos resultados também é feita nessa seção. A quinta seção sumariza as principais implicações e demonstra os cálculos da análise de viabilidade econômica com a implantação dos leitores de códigos de barras e coletores de dados com leitores RFID para a empresa. Por fim, o artigo encerra com as conclusões, limitações e sugestões de pesquisas futuras. 


\section{Gestão Logística}

A gestão de suprimentos não podes enfatizar apenas processos logísticos. O esperado é que contemple todos os processos de negócios relacionados aos requisitos dos clientes finais (Santos \& Alves, 2015). A proposta de criação de um sistema de melhoria nos processos logísticos da empresa de medicamentos veterinários analisada surgiu a partir da constatação de um grande número de retrabalhos.

As principais fontes de retrabalho gerada estão associadas a divergências nas quantidades de medicamentos a serem separados, produtos que foram enviados aos clientes sem haver a solicitação, e assim por diante. Os dados históricos da empresa investigada apontam que em média $25 \%$ útil de trabalho diário é perdido com retrabalhos, devido ao processo ineficiente utilizado pela empresa no setor de logística e distribuição.

É possível afirmar que a logística potencializa a adição de valor através da eficiência, eficácia e diferenciação. Afinal, não basta vender o produto. Faz-se necessário entregar o produto no prazo, com qualidade e custo justo (Rodriguez, 2004). Além disso, para se entender a influência do posicionamento estratégico da empresa sobre o desempenho da cadeia de suprimentos é importante considerar o nível de relacionamento com fornecedores, os critérios de seleção de fornecedores, o dimensionamento da base de fornecedores entre outros parâmetros (Storti et al., 2018).

Por isso as empresas precisam monitorar se os processos logísticos estão sendo eficientes, no que tange a um bom armazenamento e distribuição. A logística pode ser considerada uma fonte de vantagem competitiva sustentável. Em ambientes competitivos, a constante capacitação da equipe de logística se torna uma práticas indispensável. Através da logística as empresas procuram vantagem competitiva que permite sobreviver à atual economia mundial (Bigaton, 2004).

Além disso, com o avanço tecnológico, é necessário implementar e tecnologias que facilitam o recebimento, o manuseio e a saída das mercadorias, minimizando avarias, trocas e retrabalhos. Razzolini (2007) corrobora afirmando que, quando se pensa em desenvolvimento de uma nação, é necessário pensar em infraestrutura necessária para que tal fato aconteça. Sob a ótica logística, é necessário dotar as regiões de maior movimentação de cargas de infraestrutura, de modo a reunir todas as facilidades indispensáveis para melhorias das eficiências da eficiência logística.

De acordo com Russo (2009) na maioria das situações não é possível eliminar com completo os estoques. Portanto, deve-se estocar as quantidades adequadas para se reduzir custos relativos à armazenagem. O controle do estoque de segurança, por exemplo, deve ser mensurado pela demanda de seus produtos. Contudo, alguns produtos podem requerer ser estocados em quantidades maiores devido às taxas de rotatividade elevadas.

Anteriormente, o que era visto apenas como uma redução de custos começa a ser entendido como um diferencial agregado ao produto, conquistando dessa forma o cliente que passa a exigir preço competitivo (Oliveira, 2008). É possível dizer ainda que a logística evolui gradativamente junto com a demanda, exigindo atualmente movimentações rápidas e precisas.

As novas práticas de gestão logística vieram para aprimorar os processos tornando o fluxo das informações ágeis, proporcionando aumento da lucratividade (Lago et al., 2008). Assim, de forma geral, a logística pode ser definida como um processo eficaz de planejamento, 
implementação e controle de fluxo de materiais. Incluindo as atividades mais importantes para disponibilizar os bens e serviços aos consumidores onde e quando desejarem (Ballou, 2006).

Para a gestão logística, o gerenciamento dos custos da atividade é essencial para a competitividade empresarial, facilitando assim a mensuração dos resultados e proporcionando vantagens em um mercado cada vez mais competitivo. Por fim, é possível ainda afirmar que, empresas que hoje não possuem uma boa gestão dos processos logísticos, terão dificuldades no controle de seus estoques, resultando em um serviço de baixa qualidade e baixa agregação de valor ao produto (Martins et al., 2005).

\section{Distribuição Logística e Tecnologia da Informação}

O papel da área de logística para o desempenho das organizações são de sumária importância. Nesse âmbito, é nítido que os meios tecnológicos tradicionais oferecidos hoje, tais como computadores e calculadoras, não estão sendo mais suficientes para atender as demanda de trabalho como em décadas passadas. O fluxo de informações é um dos componentes que influenciam a gestão da demanda e a variabilidade dos estoques na cadeia de suprimentos normalmente decorrente dos problemas de comunicação (Santos \& Alves, 2015).

Portanto, há a necessidade da implantação massiva de dispositivos controladores, tais como os leitores de código de barra ou sistemas RFID. Algumas empresas encontram-se em estágios mais avançados de adoção da RFID. Por exemplo, diversas empresas do setor varejistas ao redor do mundo, vêm induzindo a adoção de RFID em seus fornecedores. Como por exemplos, as cadeias varejistas Metro e as redes de supermercados Tesco e WalMart (Pedroso et al., 2009). Os autores afirma que a tecnologia RFID (Figura 1) usa ondas eletromagnéticas de rádio frequência para comunicar os dados de identificação de algum elemento. Como por exemplo, produtos, componentes, caixas, pallets, containers, veículos, máquinas etc.

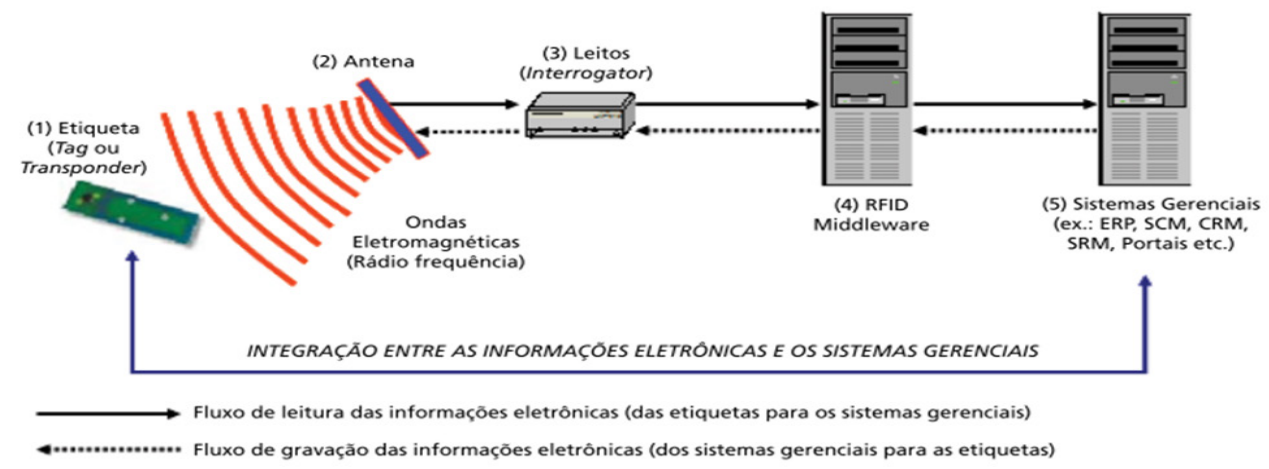

Figura 1. Funcionamento de sistemas RFID.

Fonte: Pedroso et al. (2009).

Segundo afirma Dornier (2012), atualmente a tecnologia oferece novos recursos para a logística assim como em outras áreas da empresa, transformando a forma como funciona a gestão de operação logística. Um exemplo em particular é o uso de leitores de códigos de barra e o intercâmbio eletrônico de dados (EDI - Electronic Data Interchange) melhorando a velocidade e a acuracidade da informação. 
A distribuição logística por sua vez, pode ser compreendida como um sistema de entrega de produtos aos seus clientes. Consequentemente, a eficiência da distribuição pode acrescentar valor ao produto, reduzindo custos e garantindo que o produto esteja no lugar e momento certo. Para Oliveira e Oliveira (2005), a geração de valor vem da satisfação do cliente pela qualidade apresentada e disponibilidade de seu pedido.

Existem diversas estratégias capacitadoras de geração de valor para os clientes, sejam elas através de benefícios individuais, tais como premiações, ou sejam elas através de vantagens intangíveis, tais como disponibilidade, facilidade e rapidez diferenciada no atendimento. Assim sendo, é possível afirmar que os processos logísticos, quando voltados para o cliente, resultam em vantagem competitiva. A logística deve se preocupar também com o fluxo de informações buscando atender as necessidades e expectativas de seu consumidor final (Braido \& Martens, 2012).

É possível afirmar que as aplicações e boa parte dos softwares usados pelas empresas para o gerenciamento logísticos usados no passado, atendiam várias funções, embora não eram habilitados a comunicar-se entre si. Isso resultava em morosidade nos processos. Branski e Lauriano (2013) corroboram afirmando que um conjunto de informações isoladas fazem com que os processos não contribuam para a competitividade, resultando em baixo desempenho. Por sua vez, as novas ferramentas de tecnologia de informação vieram para acelerar os processos, trazendo veracidade às informações e facilitando os processos logísticos.

Há uma tendência atualmente das empresas investirem em novas tecnologias de armazenamento de dados. As organizações que valorizam o conhecimento e utilizam de forma correta as informações possuem vantagens competitivas, tornando eficientes suas tomadas de decisões (Scartezini et al., 2010). Com o mercado competitivo, as tomadas de decisões devem ser bem planejadas, minimizando ao máximo a chance de uma decisão errada, o que resultaria em retrabalho e atrasos nos processos logísticos.

Além de leitores de códigos de barra, existe uma tendência atual de uso de Sistemas de Gerenciamento de Armazéns (Warehouse Management System - WMS). Este é responsável pelo gerenciamento das funções básicas como recebimento de mercadorias, estocagem e separação, integrado a um software. Tal sistema auxilia na administração do fluxo das informações, implicando na maioria dos casos em redução dos custos com movimentações e estocagem. Um sistema WMS permite rastrear de forma automática a movimentação de materiais, endereços de armazenagem, os níveis de estoques com precisão e com agilidade por meio de leitura de código de barras, ou coletores de dados (Barros, 2005). Os coletores de dados utilizam o WMS como plataforma, abrangendo tarefas que antes eram feitas manualmente.

A gestão da informação dos processos logísticos é fundamental para o setor da logística. Isso ocorre porque a informação correta sobre os processos, aumenta a velocidade do fluxo total das informações. Para que as organizações consigam atingir seus objetivos, é imprescindível que os elementos estejam em sintonia, minimizando perdas com informações discordantes e incoerentes (Hékis et al., 2013).

As empresas estão destinado foco gerencial para os desafios envolvendo a troca eficiente de informação, seja ela interna ou externa à empresa. Neste enfoque, muitas empresas estão apostando em infraestrutura de TI direcionadas para a gestão de distribuição. Proporcionado assim, melhorias neste setor (Ribeiro \& Carvalho, 2012). 
De acordo com o foco do presente estudo, o uso de ferramentas modernas de tecnologia da informação, apresentam impactos positivos nas operações logísticas, devido ao fato de que as informações podem ser obtidas em tempo real. Entretanto, deve-se levar em conta que uma parte da logística opera considerando previsões de demandas futuras. Como consequência disso, uma informação incorreta ou atrasada pode resultar em falta ou excesso de estoque, gerando custos no processo (Beker \& Gutierrez, 2008).

Em organizações que adotam sistemas modernos, a logística empresarial está relacionadas diretamente com a perspectiva do cliente. Além de interagir de forma eficiente com processos que usam ferramentas tecnológicas que asseguram velocidade e precisão de seus estoques. As soluções usando RFID podem gerar benefícios de natureza estratégica, tática ou operacional às empresas (Pedroso et al., 2009). Assim, os leitores de códigos de barras e os leitores de rádio frequência que usam a tecnologia RFID, proporcionam tais vantagens.

\section{MATERIAIS E MÉTODOS}

A pesquisa científica é a realização de uma investigação planejada, desenvolvida de acordo com as normas da metodologia e consagrada pela ciência (Gerhardt \& Silveira, 2009). Desse modo, a pesquisa qualitativa costuma ser direcionada e não buscar enumerar eventos, pois sua ideia é de interesse amplo e, desse modo, faz parte à obtenção de dados descritivos.

Uma pesquisa qualitativa tem como característica a busca profunda de informações sobre o fenômeno em análise. Assim, na primeira etapa do presente estudo, foi realizada uma pesquisa com sete colaboradores da empresa, envolvidos com o setor da logística. $O$ objetivo foi identificar quais eram as maiores dificuldades enfrentadas nos processos e rotinas logísticos.

Nessa perspectiva, esse estudo pode ser caracterizado como sendo de natureza aplicada, realizado por meio de um estudo de caso em profundidade (Yin, 2005). A unidade de análise investigada foi o setor de distribuição de uma empresa de produtos veterinários, situada em Porto Alegre no Rio Grande do Sul, Brazil. A empresa foi fundada em 1984 e possui hoje uma filial onde está alocada o setor de logística com 18 colaboradores no total, sendo 9 alocados em específico no setor da logística e os demais em áreas administrativas.

Atualmente a empresa é líder de marcado tendo em torno de $80 \%$ das vendas desse segmento no Rio Grande do Sul. Os planos de expansão da empresa incluem implantar filiais nos estados de Santa Catarina e São Paulo. Como esse estudo se trata de uma pesquisa descritiva, está baseada em questionários e observação sistemática. A pesquisa descritiva visa descrever as características de determinada população ou fenômeno (Kauark, 2010; Gil, 2010). Uma das peculiaridades da pesquisa descritiva está na utilização de técnicas padronizadas de coleta de dados. Assim, o presente trabalho expõe a frequência em que os fenômenos relacionados aos problemas logísticos acontecem.

Na visão de Gil (2007) o estudo de caso é um método de pesquisa amplamente usado em pesquisa social, que consiste no estudo profundo e exaustivo de um ou de poucos objetos. Desse modo, o estudo de caso se torna um estudo de fenômenos reais, preservando o 
caráter unitário do objeto estudado. Alguns aspectos caracterizam o estudo de caso, tais como como uma estratégia de pesquisa, abrangendo o estudo de um fenômeno dentro de seu contexto a ser estudado. O estudo de caso pode ser único ou múltiplo e a unidade de análise pode ser um ou mais indivíduos.

A empresa distribuidora de produtos veterinários do estudo de caso em questão possui aproximadamente 500 itens no seu portfólio de produtos à venda, incluindo diversos tipos de medicamentos e rações. Quanto ao volume de transações de informações, a empresa tem um faturamento médio de 100 notas fiscais por dia. Historicamente, a empresa vem apresentando problemas relacionados a retrabalhos. Tais problemas representam cerca de $25 \%$ do tempo diário produtivo e são causados principalmente por problemas na separação e entregas divergentes da compra do cliente.

Portanto, o presente estudo analisa as implicações de novas tecnologias que, aplicadas na área de distribuição, poderão reduzir os problemas com retrabalho e divergência no estoque físico da empresa estudada. O estudo foi conduzido ao longo dos anos de 2014 e 2015. Quando mensurados os tipos de armazenamentos utilizados pela empresa atualmente, é possível constatar que o uso de códigos de barras, e coletores de dados com leitores RFID poderá contribuir para identificar as falhas existentes, como controles de estoque que ainda são conferidos manualmente no papel, além de possibilitar a redução de divergências e erros nos estoques físicos.

Na visão de Becker e Gutierrez (2008) a tecnologia é apontada como dinamizadora para melhoria nos atributos dos serviços esperados pelo cliente. Logo, o cliente espera encontrar confiabilidade, responsabilidade e segurança e customização nos processos da empresa. Ao analisarmos os impactos nos indicadores de retrabalho, percebeu-se que as possuem potencial para agregar valores ao negócios, e a imagem da empresa perante seus clientes.

\section{RESULTADOS E DISCUSSÃO}

Os processos logísticos da empresa analisada vinham historicamente passando por dificuldades que demandas muito o tempo de seus processos. Desse modo, o setor não vem conseguindo alcançar suas metas operacionais mensais, deixando de atender processos considerados importantes para a logística. Portanto, para melhor visualização dos processos da empresa, um fluxograma (Figura 2) foi elaborado com a finalidade de esclarecer o funcionamento e sequência dos processos no setor da logística. O processo de elaboração do fluxograma também contribuiu para identificar possíveis falhas que podem ser melhorados ou até mesmo alterados.

Segundo o gestor na área de logística, a empresa possuía um bom aproveitamento de seus funcionários operadores logísticos. Contudo, com a implantação de uma tecnologia de conferência eletrônica de estoques, a empresa pode se beneficiar da melhoria nos tempos dos processos, e da precisão de que o pedido separado será o correto. Assim, haveria redução de retrabalhos, podendo utilizar o tempo que antes era usado com correções de erros para a separação de novos pedidos, organização do depósito, reposição de produtos nas prateleiras, treinamento de funcionários, etc. 
A empresa dividia sua distribuição entre medicamentos veterinários e rações para cães e gatos. Os estoques de rações ocupavam maior do espaço físico no depósito, pois são compradas em palets. Cada palet armazena um tipo de ração e cada tipo é classificado pela frequência de sua saída. As rações com maior saída são classificadas como "A", e as com menor saída são classificadas como "B" conforme a definição do fornecedor.

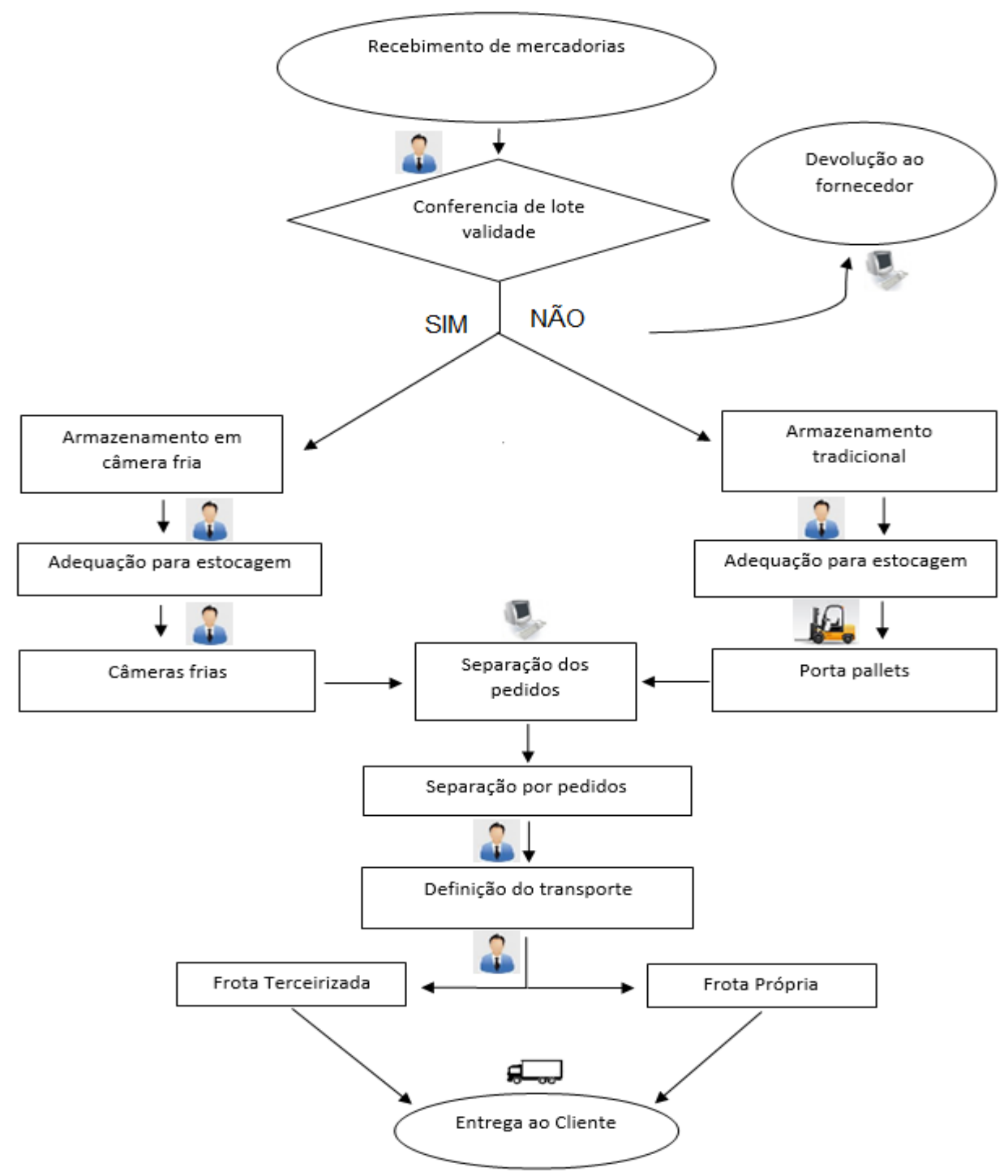

Figura 2. Fluxograma dos processos do setor de logística da empresa.

A seguir, o Tabela 1 detalha as atividades descritas no fluxograma, a fim de demonstrar as dificuldades encontradas na logística da empresa distribuidora de medicamentos veterinários. 
Tabela 1. Etapas dos processos

\begin{tabular}{|l|l|}
\hline Etapa & Descrição/Dificuldades \\
\hline Sim & Aprovação lote e validade, com prazos conforme normas da empresa. \\
\hline Não & $\begin{array}{l}\text { Lotes e validades fora do combinado com o fornecedor é feita uma nota fiscal de } \\
\text { devolução da mercadoria que voltam ao fornecedor. }\end{array}$ \\
\hline $\begin{array}{l}\text { Armazenamento } \\
\text { Tradicional }\end{array}$ & $\begin{array}{l}\text { Produto não requer refrigeração, será armazenado, se em pouca quantidade, no } \\
\text { seu próprio espaço, e se em grande quantidade será armazenado em porta pallets } \\
\text { com auxílio de empilhadeiras apropriadas. }\end{array}$ \\
\hline Ermazenamento câmera fria & $\begin{array}{l}\text { Alguns produtos como vacinas requerem armazenamentos em temperaturas entre } \\
2^{\circ} \text { e } 8^{\circ} \text { graus são armazenados em câmeras frias }\end{array}$ \\
\hline Separação dos pedidos & $\begin{array}{l}\text { Os separadores recebem do CPD (Central de Processamentos de Dados) uma } \\
\text { lista reunindo vários pedidos a serem separados. }\end{array}$ \\
\hline Separação por pedidos & $\begin{array}{l}\text { Cada separador separa um pedido de cada vez, definindo qual será o transporte } \\
\text { adequado para o mesmo, se próprio ou terceirizado. }\end{array}$ \\
\hline Frota Terceirizada & $\begin{array}{l}\text { A empresa dispõe de parcerias com transportadoras terceirizadas para agilizar a } \\
\text { entrega para longos destinos. }\end{array}$ \\
\hline Frota & \begin{tabular}{l} 
Dispomos de 5 veículos para entregas em Porto Alegre e grande Porto Alegre. \\
\hline
\end{tabular}
\end{tabular}

\section{Processo de armazenagem convencional}

Esta etapa refere-se ao tipo de armazenamento feito na empresa para estocar os produtos que chegam dos fornecedores no depósito. Devido à falta de gestão correta nas quantidades a serem compradas, historicamente as aquisições eram feitas em excesso. Como consequência, produtos com pouca rotatividade ultrapassem seu prazo de validade, gerando custos, que poderiam ser evitados. Desse modo, as compras em excesso vêm dificultando e atrasando os processos da área da logística.

Já a falta de eficiência no armazenamento acontecia por falta de planejamento nas compras. Considerando que as quantidades são compradas acima da demanda necessária, ocasionando acúmulo das mercadorias, o resultado é que os estoques ocupam os espaços que devem ser destinados a outras mercadorias. Tal prática contraria as orientações de Santos e Alves (2015) sobre a necessidade de coordenar a demanda entre os membros da cadeia de suprimentos e o cliente final.

\section{Processo de armazenagem em câmaras Frias}

Os armazenamentos nas câmaras frias servem para os produtos de alta perecibildiade, tais como as vacinas e medicamentos. Esses item necessitavam estar com temperatura controlada entre $2^{\circ}$ e $8^{\circ}$ graus. No enfoque do trabalho, uma das melhorias sugeridas foi transferir as vacinas das caixas de isopor - como chegam à empresa - para caixas plásticas vazadas, pois facilitam a circulação do ar entre as mesmas.

Como acontece no armazenamento tradicional, as vacinas também eram compradas com uma quantidade superior a sua rotatividade, formando acúmulo do mesmo produto nas duas câmaras frias, dificultando o acesso a outras vacinas e o controle correto de lotes e de validades. 


\section{Processo de manuseio e estocagem}

Como as vacinas estavam, em geral, adequadamente organizadas para sua correta estocagem, os palets de rações também deveriam seguir o mesmo procedimento. Contudo, as rações eram compradas em quantidades além do espaço físico disponível para o seu armazenamento. Consequentemente, não era possível definir posições fixas para cada tipo de ração desrespeitando a classificação "A" e "B". Assim, os palets em excesso ficavam armazenados fora do seu local específico. O efeito geral de todos esses problemas é a geração de atrasos no processos de separação de itens para os clientes, uma vez que para manusear uma ração que está atrás desse palet, faz-se necessário efetuar o manuseio e a troca de lugar.

\section{Processo de separação dos pedidos}

Ao ser liberado um grupo de pedidos, a empresa elaborava uma listagem dos produtos para facilitar a separação e a coleta dos medicamentos que eram separados por pedidos individuais a cada cliente. Devido ao fato de que os pedidos eram separados manualmente, sem 0 uso de conferência eletrônica/digital, frequentemente aconteciam erros nas separações. Os erros comuns incluem: a separação de quantidades erradas e trocas de produtos, ocasionando retrabalhos, pois uma nova conferência em pedidos que já haviam sido separados anteriormente.

Através das tabelas abaixo são expostos uma série de dados quantitativos que ajudam a entender as atividades demandadas para o faturamento, bem como as maiores dificuldades apresentadas na área da logística da empresa. A Tabela 2 expõe a quantidade de notas fiscais faturadas por mês, quantas notas fiscais tiveram $100 \%$ de acertos, quantas tiveram erros na separação e quantas chegaram erradas ao cliente, resultando em retrabalhos e na necessidade de separar novamente os produtos para fazer o acerto na entrega.

Tabela 2. Quantidade de notas fiscais

\begin{tabular}{l|c|c|c}
\hline \multicolumn{1}{c|}{ Dados } & Janeiro & Fevereiro & Março \\
\hline $\begin{array}{l}\text { Notas fiscais faturadas } \\
\text { (unidades) }\end{array}$ & 3500 & 3200 & 2800 \\
\hline $\begin{array}{l}\text { Acertos na separação } \\
\text { (unidades) }\end{array}$ & 3350 & 3070 & 2710 \\
\hline $\begin{array}{l}\text { Erros na separação } \\
\text { (unidades) }\end{array}$ & 150 & 130 & 90 \\
\hline $\begin{array}{l}\text { Retrabalhos de separação } \\
\text { (unidades) }\end{array}$ & 60 & 43 & 36 \\
\hline
\end{tabular}

A Tabela 3 por sua vez apresenta como eram efetuadas as compras de medicamentos veterinários em excesso de seus fornecedores. A área destinada aos medicamentos dispõe de um espaço físico de $140 \mathrm{~m}^{2}$ ao total. Desse modo, as compras em excesso ocupam espaços que seriam destinados originalmente para realizar a passagem, porém as mesmas ficam dificultando a locomoção e separação dos pedidos, causando atrasos na separação. 
Tabela 3. Área ocupada pelas compras em excesso em $\mathrm{m}^{2}$

\begin{tabular}{l|c|c|c}
\hline \multicolumn{1}{c|}{ Dados } & Janeiro & Fevereiro & Março \\
\hline Compras de medicamentos $\left(\mathrm{m}^{2}\right)$ & 58 & 50 & 40 \\
\hline Espaço físico disponível $\left(\mathrm{m}^{2}\right)$ & 30 & 40 & 25 \\
\hline Compras excedentes $\left(\mathrm{m}^{2}\right)$ & 28 & 10 & 15 \\
\hline
\end{tabular}

A análise das Tabelas 2 e 3 evidencia que não havia uma gestão correta dos processos de compras de medicamentos. Historicamente eram feitas compras além do espaço físico destinado a cada produto. Logo, não havia como manter cada medicamento em seu lugar destinado, se fazendo necessário trocá-lo de lugar cada vez que o mesmo é comprado em excesso. Isso implica que os medicamentos ficavam estocados com o endereçamento incorreto.

O excesso de compras acontecia também na família de produtos de rações. Existe na empresa 156 posições ao todo em dois porta palets. As rações classificadas como "A" possuem 3 posições para cada tipo. Já as rações classificadas como "B", têm 2 posições para cada tipo. Ainda existem 5 posições extras para quando um tipo de ração é comprado em excesso são destinadsa para as posições extras e, quando excedem, as posições extras ficam no chão dificultando a separação dos pedidos.

Tabela 4. Compras de rações em excesso

\begin{tabular}{l|c|c|c}
\hline \multicolumn{1}{c|}{ Dados } & Classificação "A" & Classificação "B” & Palets em excesso \\
\hline Janeiro (palets) & 6 & 4 & 5 \\
\hline Fevereiro (palets) & 9 & 4 & 8 \\
\hline Março (palets) & 6 & 3 & 4 \\
\hline
\end{tabular}

A Tabela 4 reitera como a compra de ração excede o espaço físico disponível, forçando que palets de rações sejam deixados no chão dificultando a separação de um produto que está no porta palet. Assim, o operador responsável pela separação é obrigado a primeiro movimentar o palet para outro local antes de pegar o produto procurado. Diante disso, é possível indicar que a implantação da conferência eletrônica se faz necessária, visando reduzir tais custos com entregas e retrabalhos. É possível sugerir que o tempo que é utilizado para a procura e troca deposição de mercadorias, com a automatização, seria usado para efetuar a separação de mais pedidos. Após sua separação, haveria a conferência eletrônica, aumentando a acuracidade de que os pedidos não precisarão de troca de produto ou de quantidades.

A empresa atualmente trabalha com vários laboratórios fornecedores fabricantes de medicamentos. Portanto, a empresa cumpre metas de compra em toda a linha de medicamentos fabricada pelo laboratório. Alguns produtos fabricados pelo laboratório tem alta rotatividade, enquanto que outros não. Quando comprados em excesso, os produtos tem sua validade ultrapassada, gerando custos desnecessários à empresa por falta de gestão de compras.

O diagnóstico realizado durante a pesquisa permitiu exemplificar as perdas que a empresa 
está tendo proveniente dos erros na separação de seus produtos. Assim, são detalhados exemplos de erros na separação que aconteceram no mês de outubro de 2014. A Tabela 5 demonstra três exemplos de entregas que apresentaram erros, como troca de produtos, divergência na quantidade pedida pelo cliente e falta de mercadoria. Nestes três casos, o cliente optou por devolver toda a mercadoria e receber novamente apenas quando a entrega estivesse correta. O efeito desse tipo de problema é que, como o pedido foi entregue por uma transportadora terceirizada, isso resultou em mais dois tipos de custos adicionais: o custo de retorno/devolução e o custo para ser novamente entregue.

Tabela 5. Custos de fretes gerados por retrabalhos

\begin{tabular}{l|c|c|c}
\hline Fretes gerados com retrabalhos & $\begin{array}{c}\text { São Lourenço do Sul } \\
\text { US\$ }\end{array}$ & $\begin{array}{c}\text { Santa Maria } \\
\text { US\$ }\end{array}$ & $\begin{array}{c}\text { Lajeado } \\
\text { US\$ }\end{array}$ \\
\hline Frete para a entrega em US\$ & 10 & 7,5 & 10 \\
\hline Motivo do retrabalho & Faltou 1 item & $\begin{array}{c}\text { Erros na } \\
\text { quantidade }\end{array}$ & Produto trocado \\
\hline $\begin{array}{l}\text { Frete gerado para o retorno em } \\
\text { US }\end{array}$ & 5 & 3,75 & 5 \\
\hline $\begin{array}{l}\text { Frete gerados para a entrega } \\
\text { novamente }\end{array}$ & 10 & 7,5 & 10 \\
\hline $\begin{array}{l}\text { Totais dos custos com erros em } \\
\text { US\$ }\end{array}$ & 15 & 11,25 & 15 \\
\hline
\end{tabular}

Aempresa realizava a conferência do estoque diariamente, porém nos exemplos supracitados, as transportadoras já haviam coletado os pedidos, e não foi possível fazer a correção dos erros antes que o pedido saíssem para a entrega aos clientes. Atualmente a empresa vem movendo ações para reduzir os custos com fretes. Entretanto, a ausência da conferência eletrônica inviabilizam as reduções de custos esperados.

Além disso, foi feita a comparação ilustrativa de um mês para outro, resultando em pouca redução nos índices de erros na separação de estoques. Os números reforçaram que se faz necessária a implantação da conferência eletrônica, trazendo certeza que os pedidos estarão corretos, sem troca e sem diferença nas quantidades dos medicamentos. Tal necessidade é corroborada por estudos recentes da literatura. Storti et al. (2018), por exemplo, afirmam que o sucesso de uma empresa pode estar relacionado à estratégia da gestão de seus fornecedores e ao fluxo de informações da cadeia de suprimentos. Portanto, a Tabela 6 demonstra as perdas financeiras decorrentes de trocas ou faltas de produtos em pedidos separados no início do segundo trimestre de 2014, que foram enviados por transportadoras terceirizadas.

A média de retrabalhos dos últimos cinco meses foi calculada da seguinte maneira: US\$ 2847,7 dividido por 6 (meses), resultando em US\$ 474,6 em custos gerados por fretes causados por retrabalhos. 
Tabela 6. Custos gerados por fretes com retrabalhos

\begin{tabular}{l|c|c|c|c}
\hline $\begin{array}{c}\text { Custos gerados com } \\
\text { erros na separação de } \\
\text { pedidos }\end{array}$ & $\begin{array}{c}\text { Custos com frete } \\
\text { para retrabalho } \\
\text { (US\$) }\end{array}$ & $\begin{array}{c}\text { Custo com perdas } \\
\text { de produtos } \\
\text { (US\$) }\end{array}$ & $\begin{array}{c}\text { Custo com correção } \\
\text { da entrega própria } \\
\text { (US\$) }\end{array}$ & $\begin{array}{c}\text { Custos } \\
\text { Totais } \\
\text { (US\$) }\end{array}$ \\
\hline Abril & 517,5 & 75 & $17,5 / 190 \mathrm{~km}$ & $\mathbf{6 1 0}$ \\
\hline Maio & 445 & 137,5 & $7,5 / 67 \mathrm{~km}$ & $\mathbf{4 8 0}$ \\
\hline Junho & 465 & 0 & $4,5 / 45 \mathrm{~km}$ & $\mathbf{4 6 9 , 5}$ \\
\hline Julho & 487,5 & 23,2 & $11,2 / 95 \mathrm{~km}$ & $\mathbf{5 2 2}$ \\
\hline Agosto & 395 & 18,7 & $10 / 85 \mathrm{~km}$ & $\mathbf{4 2 3 , 7}$ \\
\hline Setembro & 312,5 & 12,5 & $7,5 / 67 \mathrm{~km}$ & $\mathbf{3 3 2 , 5}$ \\
\hline Total & $\mathbf{2 6 2 2 , 5}$ & $\mathbf{1 6 7}$ & $\mathbf{5 8 , 2}$ & $\mathbf{2 8 4 7 , 7}$ \\
\hline
\end{tabular}

\section{Oportunidades de melhorias nos processos logísticos da empresa investigada}

É notável que a tecnologia da informação vem facilitando e agilizando os processos na área da logística em empresas modernas. Nas atividades envolvendo o recebimento de mercadorias, um leitor de códigos de barra facilitaria a entrada dos produtos que chegam dos fornecedores à empresa. Pelo código de barra já cadastrado, é possível saber nome do produto, tamanho, lote, validade, havendo apenas a necessidade de digitar a quantidade recebida.

Para auxiliar no armazenamento correto do produto, o código de barras estando cadastrado, repassará as informações para o sistema que deveriam ser digitados. Assim seria necessário apenas efetuar a digitação da quantidade que está sendo recebida de produtos, pois o código de barras permite armazena dados como por exemplo, o nome do medicamento, lote, validade, endereçamento e etc.

$\mathrm{Na}$ separação de pedidos, a tecnologia da informação dá agilidade aos processos. A implantação de um leitor de códigos de barras apresentaria resultaria em exatidão no final da separação de um pedido certificando que não existirá troca de produtos, de lotes ou de validade diferente ao selecionado ou em falta.

Além disso, foi evidenciado que a empresa destinava em média $25 \%$ do seu tempo diário útil para a resolução de trocas e faltas de medicamentos nos pedidos separados. Portanto, a partir da implantação da conferência eletrônica, resultaria em redução do tempo gasto para corrigir pedidos já separados e tal tempo seria usado para a separação de novos pedidos. A implantação de leitores de códigos de barra ou coletores de dados nas atividades de logística de distribuição da empresa analisada resultaria nas seguintes principais vantagens apresentadas na Tabela 7:

Tabela 7. Vantagens dos leitores e coletores de dados

\begin{tabular}{|l|c|c|}
\hline \multicolumn{1}{|c|}{ Comparação } & Leitor de código de barras & Coletor de dados \\
\hline Baixo custo na sua implantação & $\checkmark \rightarrow$ & Auto custo na sua implantação \\
\hline Separação correta de pedidos. & $\checkmark \rightarrow$ & $\checkmark \rightarrow$ \\
\hline Acuracidade no estoque. & $\checkmark \rightarrow$ & $\checkmark \rightarrow$ \\
\hline Redução de tempo nos processos & $\checkmark \rightarrow$ & $\checkmark \rightarrow$ \\
\hline Informações em tempo real & $\checkmark \rightarrow$ & $\checkmark \rightarrow$ \\
\hline Segurança nas informações & $\checkmark \rightarrow$ & Alta \\
\hline Custo com manutenção & Baixa & $\checkmark$ \\
\hline
\end{tabular}


Na Tabela 8 é apresentado ainda um comparativo entre o tempo de separação com a conferência manual que é utilizada atualmente, e qual será a vantagem da empresa na separação e conferência após a implantação de uma conferência eletrônica.

Tabela 8. Comparação dos tempos usados nos processos

\begin{tabular}{l|c|c}
\multicolumn{1}{c|}{ Tempo utilizado nos processos } & Conferência Manual & $\begin{array}{c}\text { Conferência } \\
\text { eletrônica }\end{array}$ \\
\hline Coleta de produtos para separação (minutos) & 3 & 3 \\
\hline Conferência na mesa antes da separação (minutos) & 3 & 0 \\
\hline Separação dos pedidos (minutos) & 4 & 4 \\
\hline
\end{tabular}

A Tabela 9 expõe um comparativo que mostra em qual processo da logística será otimizado o tempo na separação de novos pedidos e organização de produtos que chegam dos fornecedores.

Tabela 9. Tempos a serem reutilizados nos processos da logística

\begin{tabular}{l|c|c|c}
\hline Economia de tempo nos processos & $\begin{array}{c}\text { Conferência } \\
\text { manual }\end{array}$ & $\begin{array}{c}\text { Conferência por } \\
\text { leitor de código } \\
\text { de barras }\end{array}$ & $\begin{array}{c}\text { Tempo a serem } \\
\text { reutilizados em } \\
\text { (minutos) }\end{array}$ \\
\hline Coleta de produtos para separação & 3 & 3 & 0 \\
\hline Conferência na mesa antes da separação & 3 & 0 & 300 \\
\hline Separação dos pedidos & 4 & 4 & 0 \\
\hline
\end{tabular}

Totais baseados na separação média de 100 pedidos e tempos em minutos.

Com a implantação de leitores de códigos de barra nas atarefas de coleta dos produtos e na separação dos pedidos a empresa se beneficiaria da redução do tempo gastos realizando o acertos de pedidos e que foram separados com divergências. Esse montante represente aproximadamente $60 \%$ do tempo diário de trabalho.

Tabela 10. Descrição detalhada dos custos

\begin{tabular}{l|c}
\multicolumn{1}{c|}{ Descrição } & $\begin{array}{c}\text { Custo das implantações } \\
\text { (US\$) }\end{array}$ \\
\hline Custo com leitores de códigos de barra (9un) & 2565 \\
\hline Custo com a implantação & 315 \\
\hline Total dos custos de investimento com os leitores de códigos de barra & $\mathbf{2 8 8 0}$ \\
\hline Custos com fretes para retrabalhos & 2622,5 \\
\hline Custos com perdas de medicamentos & 167 \\
\hline Custos com correções com entregas próprias & 58,2 \\
\hline Totais dos custos com fretes e perdas & $\mathbf{2 8 4 7 , 7}$ \\
\hline
\end{tabular}

O impacto e viabilidade econômica foi calculado usando indicadores tradicionais de Engenharia Econômica. O fluxo de caixa foi calculado de acordo com as diretrizes de Ross et al.,(2009). Para calcular os indicadores de viabilidade econômica do investimento com 
as novas tecnologia, após identificado os custos de implantação (Tabela 10), foi estimado o retorno obtido com as reduções de custos nos processos logísticos da empresa. Desse modo, o fluxo de caixa apresenta resultados (Tabela 11) que facilitam analisar todos os custos com as movimentações financeiras, oferecendo subsídios para calcular outros indicadores que vão avaliar se o investimento é viável ou não para a empresa.

Tabela 11. Fluxo de caixa livre de aquisição dos equipamentos

Fluxo de caixa livre mensal da aquisição de equipamento e maquinas em US\$

\begin{tabular}{|c|c|c|c|c|c|c|c|}
\hline Período & Mês 0 & Mês 1 & Mês 2 & Mês 3 & Mês 4 & Mês 5 & Mês 6 \\
\hline $\begin{array}{l}\text { Economias com } \\
\text { retrabalhos }(+) \\
\text { (previsão de } 50 \% \text { ) }\end{array}$ & & 237,3 & 237,3 & 237,3 & 237,3 & 237,3 & 237,3 \\
\hline $\begin{array}{l}\text { Economia com mão } \\
\text { de obra }(+)\end{array}$ & & 266,9 & 266,9 & 266,9 & 266,9 & 266,9 & 266,9 \\
\hline $\begin{array}{l}\text { Depreciação dos } \\
\text { equipamentos ( - ) }\end{array}$ & & 576 & 576 & 576 & 576 & 576 & 576 \\
\hline Lucro bruto & & $-71,7$ & $-71,7$ & $-71,7$ & $-71,7$ & $-71,7$ & $-71,7$ \\
\hline Investimento ( - ) & \multicolumn{7}{|c|}{$-11.520,00$} \\
\hline $\begin{array}{l}\text { Total dos impostos } \\
(34 \%)(-)\end{array}$ & & $-24,4$ & $-24,4$ & $-24,4$ & $-24,4$ & $-24,4$ & $-24,4$ \\
\hline $\begin{array}{l}\text { Depreciação dos } \\
\text { equipamentos }(+)\end{array}$ & & 576 & 576 & 576 & 576 & 576 & 576 \\
\hline Fluxo de caixa total & & 551,6 & 551,6 & 551,6 & 551,6 & 551,6 & 551,6 \\
\hline Taxa de atratividade & \multicolumn{7}{|c|}{$8,50 \%$} \\
\hline VPL & \multicolumn{7}{|c|}{ US $\$ 884,8$} \\
\hline TIR & \multicolumn{7}{|c|}{$4 \%$} \\
\hline
\end{tabular}

Para calcular o fluxo de caixa usou-se como base $50 \%$ da média dos custos em um período de seis meses. A partir da obtenção do valor de fluxo de caixa gerado com a implantação das automatizações de tecnologia da informação, foi possível calcular os indicadores de viabilidade de Taxa Interna de Retorno (TIR), o Retorno sobre o investimento (Payback) e o Valor Presente Líquido (VPL) conforme demonstra a Tabela 11. O VPL permite comparar um investimento inicial com seus retornos futuros, utilizando uma taxa de $8,5 \%$ anual com taxa de desconto. O resultado do cálculo apresentou que o investimento estudado é viável, pois o resultado foi positivo, ou seja, o investimento para a empresa iria gerar vantagens financeiras para a empresa superiores, por exemplo, do que realizar aplicações em títulos públicos.

A TIR foi calculada conforme as premissas apresentadas por Gitman (2010), que afirma que a TIR consiste na taxa de desconto que faz com que o VPL de uma oportunidade de investimento seja igual a US\$0. Ou seja, é a taxa de retorno anual composta que a empresa obterá se investir no projeto e receber as entradas de caixa previstas. Para este investimento na empresa, a TIR apresentou uma porcentagem de $4 \%$ ao mês, comprovando que é viável investir nos leitores de códigos de barra. Ao se comparar 4\% com a taxa de atratividade do mercado financeiro brasileiro de $8,5 \%$ anual, transformando a mesma para mensal ficaria teríamos 8,5\% dividido por 12 meses, resultando em 0,70 \% ao mês. Logo, a TIR de 4\% 
mensal, apresentada no cálculo, supera e viabiliza o investimento.

Para o cálculo do indicador de Payback, foram usados como base os métodos apresentados por Ross et al. (2009) que afirmam que o período de Payback é um tipo de medida de "ponto de equilíbrio", ou seja, é o tempo necessário para recuperar o total do investimento realizado. A Tabela 12 apresenta o fluxo de caixa simples e o fluxo de caixa acumulado, facilitando a interpretação do cálculo do Payback.

Tabela 12. Demonstração dos fluxos de caixa para calcular o Payback

\begin{tabular}{c|c|c|c|c|c|c|c}
\hline Meses & Mês 0 & Mês 1 & Mês 2 & Mês 3 & Mês 4 & Mês 5 & Mês 6 \\
\hline $\begin{array}{c}\text { Fluxo de caixa } \\
\text { (US\$) }\end{array}$ & -2880 & 551,6 & 551,6 & 551,6 & 551,6 & 551,6 & 551,6 \\
\hline $\begin{array}{c}\text { Fluxo de caixa } \\
\text { acumulado } \\
\text { caixa (US\$) }\end{array}$ & -2880 & $-2328,4$ & $-1776,8$ & $-1225,2$ & $-673,6$ & $-121,9$ & 429,6 \\
\hline
\end{tabular}

De forma a facilitar a análise do cálculo do Payback e para sabermos quanto tempo o retorno será totalmente recuperado, foi usado o último mês negativo do fluxo acumulado e dividido pelo próximo mês positivo do fluxo de caixa simples. Pelo fluxo de caixa acumulado (Tabela 12), nota-se que o retorno total aconteceu entre o $5^{\circ}$ e o $6^{\circ}$ mês: US $\$ 2880$ / US $\$ 551,6=$ 5,22 . Para saber quantos dias faltarão para obter todo o retorno, utilizou-se o resultado do Payback que é 5,22. Assim tem-se que 0,22 x 12 (meses) = 2 dias, demonstrando que o retorno total do investimento acontecerá em 5 meses e 2 dias.

A partir dos resultados do cálculo do fluxo de caixa, pode-se perceber que a implantação dos leitores de códigos de barra facilitará a redução dos custos com fretes para retrabalhos. A partir da redução dos índices de troca de produtos, a empresa melhorará sua visibilidade perante seus clientes. Após feita uma análise detalhada nos processos de logística de distribuição da empresa, ficou evidente que a implantação de uma nova tecnologia de informação no setor da logística se faz necessária, para trazer confiabilidade e acuracidade no estoque e em seus processos.

Com a implantação de uma conferência eletrônica, será possível obter uma redução de custo significativa nos erros de separação, redução do tempo utilizado com correções e redução com fretes para corrigir divergências em pedidos já entregues. Logo, tais resultados obtidos nesse artigo estão em linha com os resultados dos estudos de Pedroso et al. (2009) que afirmam que a tecnologia RFID contribuiu para reduzir algumas lacunas de informação na cadeia de suprimentos, promover visibilidade em tempo real, e melhorar o monitoramento e rastreabilidade de itens, no controle de processos e na gestão dos estoques.

É importante salientar que as estimativas de redução de tempo com a implantação das automatizações e implantação de código de barras e leitoras de RFID foram definidos em conjunto com empresas especializadas do ramo da automação comercial que revendem essas tecnologias. Durante as reuniões com as empresas, foi possível identificar quais processos resultariam em maior retorno financeiro com a implantação de leitores de códigos de barras, a partir da redução de tempos, obtidas na separação de pedidos e com a redução de erros na separação. O uso da tecnologia de RFID tem sido um tema debatido nos últimos anos em empresas, na academia e também na mídia. É visto que as empresas vêm desenvolvendo 
iniciativas de RFID visando identificar possíveis aplicações (Pedroso et al., 2009).

O uso de leitor de código de barras gera velocidade nos processos, pois os dados dos produtos já estariam cadastrados no sistema a ser implantado. Assim, seria necessário apenas digitar a quantidade e validade na etapa do processo que envolve a coleta interna dos produtos para a mesa de separação melhorando a acuracidade da demanda.

Outra vantagem percebida é que os produtos passariam a ser separados de acordo com a lista demandada pelos clientes, reduzindo a necessidade de conferência manual, o que atualmente é feita na empresa após a separação dos pedidos. A atividade de gestão da demanda consiste em criar um fluxo coordenado da demanda entre os membros da cadeia de suprimentos e o cliente final (Santos \& Alves, 2015). Ainda que a automatização seja suscetível a erros, com a implantação dos leitores de códigos de barra o processo ganharia velocidade e redução dos índices de retrabalho.

No Tabela 13 é apresentado o tempo que cada atividade leva para ser realizado bem como o tempo estimado que cada processo levaria após a implantação dos leitores de códigos de barra.

Tabela 13. Comparação dos tempos antes e após a implantação dos leitores

\begin{tabular}{|c|c|c|}
\hline Atividade & $\underline{\text { Antes da implantação dos leitores }}$ & Após implantação de leitores \\
\hline $\begin{array}{c}\text { Chegada de } \\
\text { mercadoria }\end{array}$ & $\begin{array}{c}\text { Todos os dados precisam ser } \\
\text { digitados }\end{array}$ & Digita-se só a quantidade final de produtos \\
\hline $\begin{array}{c}\text { Coleta dos produtos } \\
\text { Conferência na mesa } \\
\text { de separação }\end{array}$ & $\begin{array}{c}\text { Em média } 5 \text { minutos por pedido } 10 \text { minutos para coleta de } \\
\text { cada pedido }\end{array}$ & $\begin{array}{c}\text { Separação já seria feita no momento da } \\
\text { coleta. }\end{array}$ \\
\hline $\begin{array}{c}\text { Separação de produtos necessidade de conferência } \\
\text { manual }\end{array}$ \\
\hline Conferência eletrônica & Em média 10 minutos por pedido & Já foi separado na coleta \\
\hline
\end{tabular}

A Tabela 14 abaixo sumariza e evidencia que a empresa investigada terá ganhos consideráveis em cada processamento de pedido na maior parte dos seus processos da área de distribuição.

Tabela 14. Apresentação dos ganhos de tempos nos processos

\begin{tabular}{l|c|c|c}
\multicolumn{1}{c|}{ Atividades } & Sem os leitores & Com leitores & Redução de tempo \\
\hline Na chegada de mercadoria (minutos) & 20 & 10 & 10 \\
\hline Coleta dos produtos (minutos) & 10 & 10 & 0 \\
\hline Conferência manual (minutos) & 10 & 0 & 10 \\
\hline Separação (minutos) & 10 & 0 & 10 \\
\hline Conferência eletrônica (minutos) & Não há & 5 & -5 \\
\hline Tempos com retrabalhos (minutos) & 40 & Não há & 25 \\
\hline
\end{tabular}


Os ganhos se resumem, em média, a uma redução de 50 minutos as atividades de processamento de cada pedido. Os resultados gerais da pesquisa confirmam os achados de Pedroso et al. (2009) que afirmam que a utilização de RFID é particularmente benéfica nos processos internos das empresas bem como nos processos entre empresas. Como por exemplo, nas atividades de expedição, transporte e recebimento de materiais.

\section{CONCLUSÕES}

O objetivo desta pesquisa foi analisar como as ferramentas da Tecnologia de Informação podem ser aplicadas na melhoria dos processos de distribuição logística, explorando, em particular, o impacto da implantação de duas ferramentas usadas na gestão de logística: os leitores de códigos de barras, e os coletores de dados com leitores RFID. Pretendeu assim, verificar o impacto e viabilidade de ferramentas que auxiliassem a empresa de medicamentos veterinários a reduzir o tempo gasto com retrabalhos devido a erros na separação de seus medicamentos. Para o contexto da empresa investigada, este projeto apresenta uma redução de erros na separação de pedidos, proporcionando uma economia de custos com falta de trocas de mercadorias.

Com a aplicação dos leitores de códigos de barra, foi possível projetar uma redução de custos de $50 \%$ com fretes e perdas de produtos. O estudo evidencia um retorno potencial mensal de $1,45 \%$ do valor total investido. Tal taxa de retorno, é superior aos investimentos bancários feitos atualmente pela empresa em fundos de CDB (Certificado de Depósito Bancário) e CDI (Certificado de Depósito Interbancário) que chegam a uma taxa mensal máxima de $0,85 \%$ ao mês. O estudo evidenciou que a empresa terá recuperado todo o investimento feito na implantação dos leitores de códigos de barra em um prazo de 5 meses e 2 dias. Tais resultados implicam na viabilidade de implantação, proporcionando redução dos custos e automaticamente melhorando a visibilidade de seus clientes em relação aos processos da empresa.

Os resultados deste estudo apresentam contribuições para a literatura atual e sobretudo para o contexto latino americano sobre as tecnologias aplicadas na distribuição logística. Nosso artigo foi importante para mostrar que ferramentas ligadas à tecnologia da informação, quando aplicadas corretamente, trazem inúmeros benefícios e ganhos de eficiência aos processos logísticos. Os leitores de códigos de barra, ao serem implantados na empresa, teriam como implicações principais, a redução de retrabalhos com erros na separação dos produtos e a redução de divergências de estoques. O presente estudo fornece evidências adicionais para a área de estudo mostrando que a aplicação da conferência eletrônica proporciona confiabilidade, agilidade e precisão nos processos logísticos, trazendo respostas rápidas aos clientes, melhorando a visibilidade da empresa.

A experiência de uso dessa tecnologia e os resultados da análise de viabilidade econômica foram embasados em outras empresas que já utilizam leitores de códigos de barra em sua conferência e apresentaram melhorias em todos os processos no setor da logística. A contribuição teórica e implicações da presente pesquisa, residem principalmente no fato de que esse estudo pode ser usado como fonte de pesquisa futura para avaliar o impacto da implantação dessas tecnologias em empresas de outros segmentos. Além disso, esse estudo pode também auxiliar outros estudos de campo voltados à automação logística. 
Como sugestão de trabalhos futuros para a empresa na área, é recomendado inserir as ferramentas da Indústria 4.0 no escopo do estudo feito, enfatizando o impacto e possíveis reduções de custo nos processos de controles e conferências de pedidos e dos estoques. Espera-se que esse estudo contribua para novas pesquisas neste assunto, dado o avanço da tecnologia e da Indústria 4.0 nos mercados latinos e demais regiões do globo.

\section{REFERÊNCIAS}

BALLOU, R.H. Logística empresarial: transportes, administração de materiais e distribuição física. 1.ed. São Paulo: Atlas, 1993. ISBN: 9788522408740

BALLOU, R.H. Gerenciamento da cadeia de suprimentos/logística empresarial. 5 ed.São Paulo: Atlas, 2006. ISBN: 9788536305912

BARROS, M. C. (2005), Warehouse Management System (WMS): Conceitos Teóricos e Implementação em um Centro de Distribuição. Master Dissertation, Industrial Engineering Department, Pontifícia Universidade Católica do Rio de Janeiro, Rio de Janeiro, 132 p. Disponível em: https://doi.org/10.17771/PUCRio.acad.7340

BEKER, J. C. e GUTIERREZ, R. H. (2008), Os modernos processos do sistema logístico integrado e o relevante papel da tecnologia da informação no mundo competitivo. Anais: Simpósio de Excelência em Gestão e Tecnologia. São Paulo. Brasil.

BERTAGLIA, P. R. Logística e gerenciamento da cadeia de abastecimento. 10 ed. São Paulo: Saraiva, 2006. ISBN: 9788502080959

BIGATON, A. L. e FILHO, E. (2004), Logística e a tecnologia da informação. Anais: Simpósio de Excelência em Gestão e Tecnologia - Resende, RJ, Brasil.

BRAIDO, G. M. e MARTENS, C. (2012). A gestão logística em uma empresa varejista de autopeças. RECADM- Revista Eletrônica de Ciência Administrativa 11(1), 26-47. https://doi. org/10.5329/RECADM.20121101002

BRANSKI, R. M. e LAURIANO, F. J. B. (2013). Tecnologia da informação e integração das redes logísticas. Gestão \& Produção, [em linha]. 20(2), 255-270. Disponível em : http://dx.doi. org/10.1590/S0104-530X201300020000220(2).

DORNIER, P. Logística e Operações Globais / textos e casos.1.ed.São Paulo: Atlas, 2012. ISBN: 8522425884

ECHEVERRI, S. R., OCHOA, D. E., TORO, M. P. e PEÑA, G., H. (2010). Impacto en las decisiones de la cadena de suministros de una empresa de confección de prendas deportiva acuaticas con la utilización de dinámica de sistemas. Revista Ingeniería Industrial, [em linha]. 9(1), 67-85. Disponível em: http://revistas.ubiobio.cl/index.php/Rl/article/view/66 
GERHARDT, T. E. e SILVEIRA, D. T. Métodos de pesquisa Universidade Aberta do Brasil - UAB/UFRGS SEAD/UFRGS. Porto Alegre: Editora da UFRGS, 2009. ISBN: 978-85-3860071-8

GIL, A. C. Como elaborar projetos de pesquisa. 5.ed.São Paulo: Atlas, 2010. ISBN: 85-2243169-8

GIL, A. C. Como elaborar projetos de pesquisa. 4. ed. São Paulo: Atlas, 2007 ISBN: 85-2243169-8

GITMAN, L. J. Princípios de administração financeira. Tradução Allan Vidigal, $12^{\circ}$ Ed.- São Paulo: Principles Prentice Hall, 2010. ISBN: 978-85-7605-332-3

HÉKIS, H. R., SILVA, B. C. L. C., RIBEIRO, A. L. S., BARBOSA, R. T. D. e SILVA, L. V. L. C. (2013). Análise do fluxo informacional de uma empresa do ramo alimentício do Rio Grande do Norte. Gestão \& Regionalidade, [em linha], 29 (86), 47-60. Disponível em: http://www. spell.org.br/documentos/ver/13801/analise-do-fluxo-informacional-de-uma-empresa-doramo-alimenticio-do-rio-grande-do-norte/i/pt-br

KAUARK, F. S.; MANHÃES, F. C. e MEDEIROS, C. H. Metodologia da pesquisa um guia prático.1.ed. Bahia: Via litterarum. 2010.

LAGO, E. A.; LÒTICI, K. M. e BIDTINGER, C. T. Um estudo de caso sobre a implantação de um sistema logístico flexível em uma indústria de embalagens plásticas. Anais: Simpósio de Excelência em Gestão e Tecnologia, RS, 2008.

MARTINS, R. S., REBECHI, D., PRATI, C. A. e CONTE, H. (2005). Decisões estratégicas na logística do agronegócio: compensação de custos transporte-armazenagem para a soja no estado do Paraná. Revista de Administração Contemporânea, [em linha]. 9(1), 53-78. Disponível em: http://dx.doi.org/10.1590/S1415-65552005000100004

MENEGATTI, D., DEIMLING, M. F., BARICHELLO, R. e GRANDO, M. L. Identificação do perfil logístico das empresas atacadistas de distribuição de alimentos. Anais: Simpósio de Excelência em Gestão e Tecnologia, (2012).

MORAES, J. G., ROSA, A. C., CRUZ, L.I.M. e MIRANDA, Y. C. Transição da tecnologia de códigos de barra para RFID. Em: ANAIS III FACTECLOG, São Paulo, 1-10 (2012). Disponível em: http://www.fatecguaratingueta.edu.br/fateclog/artigos/Artigo_15.pdf

MOURA, R. A. Logística: Suprimentos, Armazenagem, Distribuição: física. 1.ed. São Paulo, IMAM, 1989.

OLIVEIRA, J. L. R. e OLIVEIRA, S. L. (2005). Logística de distribuição e controle de estoques em uma distribuidora de medicamentos. Revista Produção Online, [em linha]. 5 (3), 1-22. Disponível em: ttps://doi.org/10.14488/1676-1901.v5i3.361

OLIVEIRA. C. (2007). Um Estudo Sobre Planejamento em Logística de Distribuição de Produtos para Consumo não Durável: Estudo de Caso de uma Indústria de Bebidas. Intertem@s, [em linha]. 13 (13), 2-75. Disponível em: http://intertemas.toledoprudente.edu. br/index.php/Direito/article/view/543/538 
ORJUELA-CASTRO, J. A., CARDONA-ROJAS, M. A. e CASTAÑEDA-LÓPEZ, L. V. Agricultural supply chain mango inventory model. Revista Ingeniería Industrial. [em linha]. 16 (2), 141-150. Disponível em: https://doi.org/10.22320/S07179103/2017.09

PEDROSO, M. C., ZWICKER, R. e DE SOUZA, C. A. (2009). Adoção de RFID no Brasil: um estudo exploratório. Revista de Administração Mackenzie, [em linha]. 10 (1), 12-36. Disponível em: http://dx.doi.org/10.1590/S1678-69712009000100002

RAZZOLINI, E. Logística empresarial no Brasil. 20.ed. Curitiba: Ibpex, 2007. ISBN

RIBEIRO, P. C. C. e CARVALHO, N. L. A. Inovação e cadeia de suprimentos: estudo de caso em operadores logísticos. Anais: XIX Simpósio de Engenharia de Produção - SIMPEP, Bauru, SP. (2012).

RODRIGUEZ, M. (2004). A Eficiência Logística. [em linha], Disponível em: http://www. omcconsult.com.br/artigos/a-eficiencia-logistica.

ROSS, S. A.; WESTERFIELD, R. W. e JORDAN, B. D. Princípios de Administração Financeira. 2.ed. São Paulo, 2009. ISBN: 8522426066.

RUSSO, C. P. Armazenagem, controle e distribuição. 20.ed. Curitiba: Ibpex, 2009. ISBN: 8565704963

SANTOS, R. F. e ALVES, J. M. (2015). Proposta de um modelo de gestão integrada da cadeia de suprimentos: aplicação no segmento de eletrodomésticos. Production, [em linha], 25(1), 125-142. Disponível em: http://dx.doi.org/10.1590/S0103-65132014005000013

SCARTEZINI, R.; FACCIO, K. e ECHEVESTE, M. E. S. Análise dos Requisitos de Informação para Desenvolvimento de um Sistema de Inteligência Competitiva. Anais: XVIII SIMPEP. Simpósio de Engenharia de Produção. Bauru, SP, (2010).

STORTI, A. T., PAIVA, E. e VIEIRA, L. M. (2018). Internacionalização e Relacionamentos em Cadeia de Suprimentos. Brazilian Business Review, [em linha]. 15 (6), 551-567. Disponível em: http://dx.doi.org/10.15728/bbr.2018.15.6.3

YIN, Robert K. Estudo de caso: planejamento e métodos. 3. ed. Bookman: Porto Alegre, 2005. ISBN: 573078529 